\title{
COMPARTILHAMENTO DE SABERES ACADÊMICOS E PROFISSIONAIS: UMA EXPERIÊNCIA NO ENSINO DE GRADUAÇÃO DE ENGENHARIA
}

DOI: 10.37702/2175-957X.COBENGE.2021.3594

Alice Menezes Monteiro - alicemonteiro017@gmail.com

UFMG

Rua Desembargador Cintra Neto 967

30620-100 - Belo Horizonte - MG

Leyla Marlene García Bances - leylagbances.7@gmail.com

Universidade Federal de Minas Gerais

avenida fleming 394

31910-130 - Belo Horizonte - MG

Valter Lúcio de Pádua - valter@desa.ufmg.br

UFMG

Rua Piemonte 570

31340-580 - Belo Horizonte - MG

Resumo: A concepção e proposição de ações de extensão universitária exigem, em primeira instância, o conhecimento da realidade socioeconômica e cultural das populações a serem envolvidas. Tendo em vista a grade curricular das Engenharias da Universidade Federal de Minas Gerais (UFMG) e a relevância do compartilhamento de saberes acadêmicos e profissionais associados ao meio ambiente e saneamento, a disciplina "Projetos de Extensão Universitária da Engenharia" foi concebida. As atividades foram realizadas em 2 municípios com população inferior a 20.000 habitantes, Santa Maria do Salto-MG e São Brás do Suaçuí-MG, tendo sido voltadas para trabalhadores da área de saneamento e meio ambiente. No contexto do Ensino Remoto Emergencial (ERE), foram realizadas 7 oficinas para compartilhamento de saberes entre estudantes, trabalhadores da área de saneamento dos municípios selecionados e especialistas na temática. As oficinas contemplaram os seguintes assuntos: levantamento de temáticas de interesse aos trabalhadores; recursos hídricos; resíduos sólidos; e esgotamento sanitário. Apesar das oficinas terem sido integralmente online e terem necessitarem alguns pontos de melhoria, a metodologia aplicada para a condução 
dos conteúdos demonstrou-se efetiva, tendo em vista o envolvimento de todos os 24 participantes e construção de novos saberes de forma colaborativa e participativa.

Palavras-chave: compartilhamento; saberes acadêmicos; saberes profissionais; saneamento; ensino de engenharia. 


\section{COBENCE \\ COMPARTILHAMENTO DE SABERES ACADÊMICOS E PROFISSIONAIS: UMA EXPERIÊNCIA NO ENSINO DE GRADUAÇÃO DE ENGENHARIA}

\section{INTRODUÇÃO}

As universidades cumprem papel importante dentro da sociedade e, conforme previsto no artigo 207 da Constituição Federal, elas devem gozar de autonomia didático-científica, administrativa e de gestão financeira e patrimonial, e obedecer ao princípio de indissociabilidade entre ensino, pesquisa e extensão". A extensão universitária é o meio que a universidade tem para ultrapassar o âmbito acadêmico, sendo abertos os conhecimentos ao público não universitário, e tem como objetivo principal a troca de conhecimentos, conceitos e aprendizados. O diferencial dos projetos de extensão está na educação de forma bilateral: os alunos participantes, além de compartilhar o conhecimento adquirido, absorvem os saberes, anseios, dúvidas e necessidades da comunidade, tornando-os mais sensíveis à realidade local.

No artigo 3 da Resolução n 10/2019 do CEPE (Conselho de Ensino, Pesquisa e Extensão) da UFMG, se estabelece que " $A$ estrutura curricular de cada curso de graduação deverá prever a integralização do percentual mínimo de $10 \%$ (dez por cento) da sua carga horária total por meio da Formação em Extensão Universitária". Na Resolução CNE/CES 02/2019, que trata das Diretrizes Curriculares Nacionais (DCN) dos cursos de graduação em Engenharia, é citado que: "Devem ser estimuladas as atividades acadêmicas, tais como trabalhos de iniciação científica, competições acadêmicas, projetos interdisciplinares e transdisciplinares, projetos de extensão, atividades de voluntariado, visitas técnicas, trabalhos em equipe, desenvolvimento de protótipos, monitorias, participação em empresas juniores, incubadoras e outras atividades empreendedoras". Destaca-se aqui a importância da extensão na formação acadêmica dos universitários, principalmente na compreensão da realidade de comunidades em vulnerabilidade social, e na proposição de soluções colaborativas e participativas.

A Resolução n. 07/2018 do MEC, que estabelece as diretrizes para a extensão na educação superior brasileira, evidencia a estrutura das atividades de extensão, sendo prioritárias: o contato com questões complexas do contexto social; a interação dialógica da comunidade acadêmica com a sociedade por meio de troca de conhecimento; e articulação entre ensino/pesquisa/extensão como um processo pedagógico único, interdisciplinar, político, educacional, cultural, científico e tecnológico.

A Universidade Federal de Minas Gerais (UFMG), possui a Resolução Complementar CEPE n. 01/2018, que regulamenta as Normas Gerais de Graduação. Nesta Resolução, a proposição de estratégias que visem à articulação do ensino com a pesquisa e com a extensão torna-se obrigatória na estrutura curricular. A extensão enriquece a trajetória de formação dos estudantes, propiciando conhecimentos, habilidades e atitudes focadas na construção de uma sociedade mais justa e igualitária.

Diante do contexto apresentado, a disciplina "Projetos de Extensão Universitária da Engenharia" teve como principais objetivos: compartilhar conhecimento entre estudantes 
da graduação e trabalhadores da área de saneamento; possibilitar a alunos de graduação experiência de ensino, tendo em vista o interesse de alguns em seguir a área acadêmica; e propiciar o desenvolvimento de atividades de extensão universitária no âmbito do ensino de graduação, assim como a autonomia dos estudantes na tomada de decisão.

\section{DESENVOLVIMENTO}

A disciplina "Projetos de Extensão Universitária da Engenharia" foi ofertada como optativa para o curso de Engenharia Ambiental da UFMG e contou também com a participação de uma aluna do curso de Engenharia de Produção. A primeira oferta ocorreu no $2^{\circ}$ semestre de 2020 , com uma carga horária de 45 horas. O conteúdo programático da disciplina foi dividido em 3 grandes eixos, descritos no Quadro 1:

Quadro 1 - Conteúdo Programático da disciplina "Projetos de Extensão Universitária da Engenharia"

\begin{tabular}{|c|c|c|}
\hline Introdução à disciplina & Capacitação Acadêmica & $\begin{array}{c}\text { Experiências acadêmicas } \\
\text { profissionais }\end{array}$ \\
\hline $\begin{array}{c}\text { Apresentação do } \\
\text { Plano do Curso }\end{array}$ & $\begin{array}{c}\text { Plataformas de videoconferência } \\
\text { para realizar atividades de } \\
\text { extensão universitária }\end{array}$ & $\begin{array}{c}\text { Identificação de demandas de } \\
\text { capacitação em saneamento em } \\
\text { municípios de Minas Gerais }\end{array}$ \\
\cline { 2 - 3 } & $\begin{array}{c}\text { Processos pedagógicos de Paulo } \\
\text { Freire }\end{array}$ & $\begin{array}{c}\text { Planejamento, execução e } \\
\text { avaliação de atividades de } \\
\text { extensão universitária } \\
\text { relacionadas à Engenharia }\end{array}$ \\
\cline { 2 - 4 } & $\begin{array}{c}\text { Materiais didáticos para ofertar } \\
\text { oficinas de saneamento (guias do } \\
\text { NUCASE) }\end{array}$ & $\begin{array}{c}\text { Compartilhamento de } \\
\text { experiências com profissionais } \\
\text { do nível operacional e de gestão } \\
\text { na área de saneamento e meio } \\
\text { ambiente }\end{array}$ \\
\hline
\end{tabular}

Fonte: Autoria Própria.

Os alunos foram estimulados a buscar, fora da sala de aula, informações complementares à plena assimilação dos conteúdos da disciplina, de modo a se transformarem no principal agente de seu processo de aprendizagem, passando o professor a assumir o papel de orientador, de indutor do conhecimento. Isso exigiu do professor a utilização de diferentes técnicas de ensino e, dos alunos, maior participação em atividades extraclasse, objetivando a aplicação prática do conhecimento (ensino contextualizado). Ocorreram aulas expositivas, palestras com convidados externos, grupos de discussão, trabalhos extraclasse e oficinas. Em decorrência da pandemia de COVID-19, que levou à suspensão das aulas presenciais na UFMG, foi adotado o Ensino Remoto Emergencial (ERE), o qual foi implantado em caráter temporário para "(...) desenvolver as atividades acadêmicas curriculares com mediação pedagógica assentada nas tecnologias digitais de informação e comunicação, possibilitando a interação estudante-docente-conhecimento". 


\subsection{CAPACITAÇÃO ACADÊMICA}

Anteriormente à etapa de Experiências Acadêmicas Profissionais, os alunos se dedicaram a uma Capacitação Acadêmica direcionada. No primeiro momento, os alunos com habilidades em ferramentas e softwares que potencialmente poderiam tornar as videoconferências mais dinâmicas e interativas, foram convidados a compartilhar seus conhecimentos prévios com os outros participantes da disciplina. Esse compartilhamento contemplou ferramentas de design, construção colaborativa online, e edição de vídeos.

Após, os alunos foram incentivados a realizar a leitura e resenha do livro "Pedagogia do Oprimido", de Paulo Freire. O estudo do livro visava contribuir para a assimilação e aplicação da construção de um saber bilateral e colaborativo e possibilitar o desenvolvimento individual dos alunos, principalmente para os que pretendem atuar na área acadêmica.

Como referência base para a construção da dinâmica a ser aplicada nas oficinas, foram disponibilizados os Guias do NUCASE (Núcleo Sudeste de Capacitação e Extensão Tecnológica em Saneamento Ambiental). O material disponibilizado visou propiciar aos alunos inspiração para elaborar as oficinas, pautadas em uma didática instigante e motivadora, com atividades facilitadoras das trocas de saberes. Todo o material aborda a temática de saneamento e meio ambiente, de uma forma de fácil compreensão para públicos de diferentes níveis de escolaridade.

\subsection{EXPERIÊNCIAS ACADÊMICAS PROFISSIONAIS}

$\mathrm{Na}$ etapa das Experiências Acadêmicas Profissionais foram desenvolvidas atividades de definição do público-alvo das oficinas, elaboração de conteúdo e execução das oficinas. Para a seleção dos municípios, foram considerados 5 critérios:

a) municípios com população menor que 20.000 habitantes;

b) contato pré-existente com as prefeituras;

c) municípios que em algum momento receberam estudantes da UFMG para o desenvolvimento de outras atividades;

d) municípios com o Índice de Vulnerabilidade Social predominantemente médio ou baixo;

e) municípios com a gestão de saneamento de responsabilidade da prefeitura.

O envolvimento das prefeituras no desenvolvimento das atividades de extensão foi necessário para garantir aos trabalhadores uma infraestrutura básica para o acompanhamento remoto das oficinas, como o acesso à internet e computadores.

Para contatar as prefeituras foi elaborado um roteiro básico, garantindo que o objetivo das oficinas fosse claro e não fomentasse falsas expectativas. Na abordagem, foi solicitada uma lista de trabalhadores da área de saneamento, que podiam ser do setor de resíduos sólidos, abastecimento de água ou esgotamento sanitário.

Como forma de criar um vínculo com os trabalhadores previamente às oficinas, assim como definir melhor o perfil dos participantes, os alunos entraram em contato com cada profissional indicado pelas prefeituras. Os trabalhadores de São Brás do Suaçuí eram em sua totalidade da área de resíduos sólidos, enquanto os trabalhadores de Santa Maria do Salto tinham atuação nas diferentes áreas de saneamento e meio ambiente.

Em ambas as prefeituras se teve um apoio local de alunos participantes da oficina e ex-alunos da própria UFMG. O apoio local foi primordial para promover a interação com 
os trabalhadores, facilitar a melhor condução das atividades e conhecer a infraestrutura disponibilizada pelas prefeituras.

O planejamento de cada oficina era realizado com 1 semana de antecedência, de forma a decidir o conteúdo a ser abordado com base na demanda dos trabalhadores, e preparar a apresentação. O Quadro 2 apresenta de forma global o conteúdo abordado em cada oficina:

Quadro 2 - Conteúdo programado e aplicado nas oficinas

\begin{tabular}{|c|c|c|c|}
\hline Oficinas & Temática & Conteúdo & Data \\
\hline 1 & Apresentação & $\begin{array}{l}\text { Apresentação dos objetivos das oficinas; } \\
\text { alinhamento das expectativas }\end{array}$ & $11 / 02 / 2021$ \\
\hline 2 & Resíduos Sólidos & $\begin{array}{l}\text { Tempo de decomposição dos resíduos no meio } \\
\text { ambiente; compartilhamento de desafios } \\
\text { encontrados na profissão; conceituação dos } \\
\text { métodos de disposição de resíduos (lixão, aterro } \\
\text { controlado; aterro sanitário) }\end{array}$ & $18 / 02 / 2021$ \\
\hline 3 & Resíduos Sólidos & $\begin{array}{l}\text { Dinâmica "Verdadeiro ou Falso" sobre coleta } \\
\text { seletiva; Política Nacional e Municipal de Resíduos } \\
\text { Sólidos; discussão sobre boas práticas na } \\
\text { reutilização de resíduos; conceituação e aplicação } \\
\text { da gravimetria; operação do aterro sanitário }\end{array}$ & $25 / 02 / 2021$ \\
\hline 4 & Recursos Hídricos & $\begin{array}{l}\text { Ciclo da Água; captação de água pluvial; consumo } \\
\text { de água médio por atividade cotidiana; água virtual. }\end{array}$ & $04 / 02 / 2021$ \\
\hline 5 & Recursos Hídricos & $\begin{array}{l}\text { Sistemas de abastecimento de água e soluções } \\
\text { alternativas; bacia hidrográfica; qualidade da água; } \\
\text { tratamento de água e saúde pública; cálculos e } \\
\text { curiosidades; legislação ambiental. }\end{array}$ & $11 / 03 / 2021$ \\
\hline 6 & $\begin{array}{l}\text { Esgotamento } \\
\text { Sanitário }\end{array}$ & $\begin{array}{l}\text { Reflexão sobre as fontes de poluição da água, } \\
\text { consequências e técnicas de controle; conceituação } \\
\text { da poluição pontual e difusa; parâmetros de } \\
\text { caracterização dos esgotos domésticos. }\end{array}$ & 05/05/2021 \\
\hline 7 & $\begin{array}{l}\text { Esgotamento } \\
\text { Sanitário }\end{array}$ & $\begin{array}{c}\text { Reflexão sobre a relação entre saúde e } \\
\text { saneamento; doenças associadas à falta de } \\
\text { saneamento e transmissão; discussão sobre o } \\
\text { saneamento ambiental; demonstração de sistemas } \\
\text { de esgotamento sanitário; legislação ambiental. }\end{array}$ & $12 / 05 / 2021$ \\
\hline
\end{tabular}

Fonte: Autoria Própria.

A disciplina contou com cinco alunas, sendo que para cada semana, duas eram selecionadas para conduzir as atividades da oficina. Destaca-se a importância de, na primeira oficina, ter se realizado uma "roda de conversa" com os trabalhadores, de forma a compreender as percepções individuais em relação ao meio ambiente, e alinhar as expectativas quanto ao conteúdo das oficinas em si. Para isso, propôs-se a cada participante compartilhar memórias da infância em que tiveram contato com o meio ambiente.

Todas as oficinas tiveram a presença do professor orientador, que tinha a função de observar os alunos e, posteriormente, fomentar a discussão de pontos de melhoria. Além 
disso, foram convidados especialistas nos assuntos abordados a cada semana (mestrandos, doutorandos ou outros professores), para que assistissem às oficinas e contribuíssem com suas experiências. Ao final das oficinas era previsto um momento para que o especialista pudesse contribuir com suas percepções e, ao longo das mesmas, os alunos os acionavam em caso de dúvidas e questões que surgiam.

$\mathrm{O}$ foco de todas as oficinas foi permitir o protagonismo dos trabalhadores no compartilhamento de experiências práticas e vivências na profissão. Apesar da condução ser de responsabilidade dos alunos, com participações pontuais dos especialistas, continuamente a fala era passada para os participantes de São Brás do Suaçuí e Santa Maria do Salto.

Após cada oficina, os alunos da disciplina eram motivados a fazer uma auto avaliação do seu envolvimento na atividade e do próprio conteúdo abordado, como forma de identificação de potenciais melhorias individuais e do grupo.

\subsection{MÉTODO DE AVALIAÇÃO DA DISCIPLINA}

Tendo em vista o conteúdo programático e a metodologia de ensino e aprendizagem da disciplina, foram os adotados critérios e estratégias de avaliação descritos na Tabela 1:

Tabela 1 - Método de Avaliação da disciplina

\begin{tabular}{|c|c|c|}
\hline Tipo de Avaliação & Discriminação & Total \\
\hline \multirow{6}{*}{ Individual } & $\begin{array}{l}\text { Autoavaliação: atribuição de nota de } 1 \text { a } 10 \text {, levando em conta a } \\
\text { análise crítica do processo individual de aprendizagem, com } \\
\text { justificativa à nota atribuída em texto de formato livre postado em } \\
\text { formulário eletrônico disponibilizado pelo professor. }\end{array}$ & \multirow{4}{*}{$35 \%$} \\
\hline & $\begin{array}{l}\text { Observação: nota atribuída pelo professor após acompanhamento do } \\
\text { desempenho dos estudantes em fatos cotidianos e em situações } \\
\text { planejadas. }\end{array}$ & \\
\hline & Resenha do livro Pedagogia do Oprimido de Paulo Freire & \\
\hline & $\begin{array}{l}\text { Vídeo individual no qual as estudantes relataram a experiência com a } \\
\text { disciplina }\end{array}$ & \\
\hline & $\begin{array}{l}\text { Concepção e planejamento das atividades de extensão desenvolvidas } \\
\text { na disciplina }\end{array}$ & \\
\hline & $\begin{array}{l}\text { Rodas de conversa com os trabalhadores que participaram das } \\
\text { oficinas }\end{array}$ & \\
\hline
\end{tabular}


Em grupo relatório com sugestões para a próxima oferta da disciplina

Fonte: Autoria Própria.

Como uma atividade em grupo, os alunos da disciplina desenvolveram para cada temática abordada um relatório de forma a sistematizar as lições aprendidas e pontos de melhorias. No final da disciplina, os alunos foram motivados a gravar um vídeo com um depoimento de toda a experiência vivenciada nas oficinas, principalmente para orientar outros alunos que vierem a se matricularem na disciplina nos próximos semestres.

\section{CONSIDERAÇÕES FINAIS}

O objetivo da disciplina foi alcançado com as oficinas ministradas, tendo-se observado o envolvimento e aprendizado compartilhado dos participantes. Notou-se uma evolução ao longo do semestre na abordagem dada às oficinas, na tentativa contínua de aplicação de dinâmicas e propostas que envolvessem os estudantes e trabalhadores das prefeituras.

O maior desafio foi o nivelamento de conteúdo que atendesse às expectativas dos participantes de Santa Maria do Salto e São Brás do Suaçuí. O nível de escolaridade e acesso a algumas informações eram distintas entre os trabalhadores dos dois municípios.

Notou-se que apenas uma semana para a preparação do conteúdo, tendo em vista o grau de envolvimento de cada aluno, foi insuficiente e sobrecarregou os estudantes em alguns momentos. Para garantir a replicabilidade e qualidade da disciplina em outros contextos, sugere-se:

a) determinação prévia e criteriosa do perfil dos trabalhadores, para não ocorrer discrepância entre os participantes que possa vir a prejudicar a condução das oficinas;

b) aumento do período para elaboração do conteúdo antes de iniciar as oficinas e promoção de encontros prévios com os especialistas, para validarem previamente o material que será apresentado.;

c) participação do professor orientador nas correções do conteúdo, visando minimizar a ocorrência de erros na apresentação para os trabalhadores;

d) apresentação prévia das oficinas, como forma de treinamento para contribuir para maior segurança das alunas ao ministrarem o conteúdo para os trabalhadores;

e) verificação com maior antecedência da estrutura de equipamento e acesso à internet nas cidades, para minimizar a ocorrência de problemas técnicos durante as oficinas;

f) existência de apoio técnico local presencial de algum ex-aluno voluntário ou aluno da disciplina, para facilitar o andamento da oficina e promover maior engajamento dos participantes;

g) proposição de tarefas aos participantes, de forma a aumentar o envolvimento deles com as oficinas. Um exemplo seria a solicitação de envio de fotos de 
atividades cotidianas realizadas no ambiente de trabalho ou de situações-problema vivenciadas no município. Além de aproximar da realidade local, fomenta-se as discussões;

h) criação de um grupo no WhatsApp com os participantes, de forma a facilitar a comunicação de todos;

i) incentivo à participação de estudantes de diferentes cursos, visando os benefícios da multidisciplinaridade;

j) memorização dos nomes dos participantes e motivação da fala deles, criando empatia entre alunos e trabalhadores;

k) mesclagem de conteúdos mais expositivos (para garantir a motivação dos participantes na aquisição de novos conhecimentos) , com conteúdos participativos, como jogos e perguntas, para a construção de um conhecimento colaborativo;

I) incorporação nas oficinas de atividades que os próprios trabalhadores realizam, considerando que eles possuem ricas experiências práticas;

m) compreensão da realidade local para uma aproximação efetiva com os participantes das oficinas;

n) oferta de certificados de participação aos trabalhadores, lanches e compensação de horas dedicadas às oficinas.

\section{Agradecimentos}

Os autores agradecem às Prefeituras dos municípios de Santa Maria do Salto-MG e São Brás do Suaçuí-MG, pelo apoio dado na realização das oficinas; aos especialistas convidados, pela contribuição na discussão do conteúdo técnico e, especialmente, aos trabalhadores que participaram das oficinas.

\section{REFERÊNCIAS}

BRASIL. Constituição. República Federativa do Brasil de 1988. Brasília, DF: Senado Federal, 1988. Disponível em: http://www.planalto.gov.br/ccivil_03/Constituicao/ConstituicaoCompilado.htm. Acesso em: 7 mai. 2021.

FREIRE, P. Pedagogia do Oprimido. RJ: Editora Paz e Terra, 256 p. Rio de Janeiro,2019.

MINISTÉRIO DA EDUCAÇÃO. RESOlUÇÃO CNE/CP No 2. Brasília, DF, 2019. Disponível em: http://portal.mec.gov.br/docman/dezembro-2019-pdf/135951-rcp002-19/file\#: :text=CONS ELHO\%20PLENO-,RESOLU\%C3\%87\%C3\%830\%20CNE\%2FCP\%20N\%C2\%BA\%202\% 2C\%20DE\%2020,DE\%20DEZEMBRO\%20DE\%202019\%20(*)\&text=Define\%20as\%20Dir etrizes \%20Curriculares\%20Nacionais,B\%C3\%A1sica\%20(BNC\%2DForma\%C3\%A7\%C3 \%A3o). Acesso em: 7 mai. 2021. 
MINISTÉRIO DA EDUCAÇÃO. RESOLUÇÃO № 7. Brasília, DF, 2018. Disponível em: http://portal.mec.gov.br/index.php?option=com_docman\&view=download\&alias=104251-rc es007-18\&category_slug=dezembro-2018-pdf\&Itemid=30192\#: :text=Estabelece\%20as\% 20Diretrizes\%20para\%20a,2024\%20e\%20d\%C3\%A1\%20outras\%20provid\%C3\%AAncias .Acesso em: 7 mai. 2021

NUCASE. NÚCLEO SUDESTE DE CAPACITAÇÃO E EXTENSÃO TECNOLÓGICA EM SANEAMENTO AMBIENTAL. GUIAS DIVERSOS PRODUZIDOS NO ÂMBITO DA RECESA, (S/D).

UFMG. COMPLEMENTAR CEPE No 01/2018. Minas Gerais, 2018. Disponível em: https://www2.ufmg.br/prograd/prograd/Pro-Reitoria-de-Graduacao/Publicacoes/Normas-G erais-de-Graduacao\#: :text=Em\%2027\%20de\%20agosto\%20de,tais\%20Normas\%20entr aram\%20em\%20vigor..Acesso em: 7 mai. 2021

UFMG. RESOLUÇÃO No 10/2019. Minas Gerais, 2019. Disponível em: https://www.ufmg.br/prograd/arquivos/docs/Res1019.pdf. Acesso em: 7 mai. 2021.

\title{
SHARING OF ACADEMIC AND PROFESSIONAL KNOWLEDGE: AN EXPERIENCE IN ENGINEERING GRADUATION TEACHING
}

\begin{abstract}
The conception and proposition of university extension actions requires, in the first instance, knowledge of the socioeconomic and cultural reality of the populations to be involved. In view of the Engineering curriculum at the Federal University of Minas Gerais (UFMG) and the relevance of sharing academic and professional knowledge associated with the environment and sanitation, the discipline "Engineering University Extension Projects" was conceived. The activities were carried out in 2 municipalities with a population of less than 20,000 inhabitants, Santa Maria do Salto-MG and São Brás do Suaçuí-MG, with a focus on sanitation and environment workers. In the context of Emergency Remote Education (ERE), 7 workshops were held to share knowledge among students, sanitation workers in selected municipalities and specialists in the subject. The workshops covered the following subjects: survey of topics of interest to workers; water resources; solid waste; and sanitary sewage. Despite the fact that the workshops were entirely online and needed some points for improvement, the methodology applied for conducting the content proved to be effective, in view of the involvement of all 24 participants and the construction of new knowledge in a collaborative and participatory way.
\end{abstract}

Keywords: sharing; academic knowledge; professional knowledge; sanitation; engineering teaching. 